\title{
The categories of grammar in resource-books of English for advanced learners
}

\section{Jana Richterová}

Charles University in Prague, Czech Republic

\begin{abstract}
The courses of morphology and syntax of the English language as linguistic disciplines studied at university level elaborate on a systematic description of the language, logically categorising the individual items of the language system. In doing so, the traditional structural terminology is employed, describing the phenomena such as complex verb phrases which may comprise modal exponents, i.e. epistemic and deontic modality, progressive and perfective aspects or the category of active vs. passive voice. As in any scientific field, the language used should provide clarity and precision and ambiguities should be avoided. In the field of applied linguistics, however, the requirement of precision in the description of the language categories seems impossible to comply with. This paper discusses the ways the categories of English grammar are defined in standard structural linguistic resources and compares them with publications in the field of applied linguistics at advanced levels. It also contrasts these against the lexical approach introduced by Lewis. The aim of the paper is to highlight the presumed discrepancies between the aforementioned types of resources and help to facilitate the ELT in the field of presenting English grammar.
\end{abstract}

Key words: descriptive grammar, communicative approach, lexical approach, general rule, tense and aspect, modal verbs;

\section{Introduction}

The ways grammar categories are presented in structural linguistic and ELT resources have long shown indisputable discrepancies. This stems primarily from the fact that 1) ELT and language learning establish a cyclic process which has been defined from a practical rather than theoretical point of view, 2) the gradually altered approach to grammar proper has re-defined teaching it. The structural view of grammar has changed from the original prescriptive into a descriptive one, while in ELT the Communicative Approach brought about the strategy of teaching 
'functions' rather than structural categories, relying on the semantics encoded in form. The question to consider is whether these new approaches bring more clarity to a student at advanced and proficiency levels, where it is accuracy that establishes the target of ELT, not the fluency or spontaneity declared for the lower levels.

When Lewis first published his book The English Verb in 1986, he addressed current ELT participants and the presentations of grammar rules in the established grammar resources. He spoke of imprecise 'catalogues of rules/meanings' presented to the learner, which lead to gradual re-defining of the once stated rules. He maintains that such 'catalogues' lead to confusion and despair of the learner, who, after a period of time, hears the rule once lain before them first contradicted, then re-formulated. Lewis unfolded for the English teachers a new view of teaching English grammar, submitting some then 'traditional' grammar books such as Thomson and Martinet's Grammar of the English language to criticism. Not only does he suggest that many of the explicit definitions and rules stated in the book are often unclear and implausible, but he also claims that such a resource book, affected with the prescriptive approach to teaching grammar, is a false concept in general. Lewis focuses on semantic notions lying behind the applied rules, clarifying the broader semantic concepts buried in the nature of English, rules which can be applied universally and which he calls 'general rules' (p. 30). Michael Swan $(1980,1989)$ seems to have a similar attitude, providing the students with less decided claims, but systematically listing 'spoken' varieties of the same category, thus following the so-called descriptive grammar.

One may agree that the descriptive-grammar approach has for long been more or less adopted by current English course-books. However, the 'catalogues of meanings' presented in course-books seem to have been both retained and outdated. Moreover, it now appears that the method of language description, where both formal and informal registers co-occur and semantics plays the main part to some extent, ignores the potential ambition of the course-book user to reach real proficiency, or to acquire the 'standard', or so-called formal register. Like with the courses where the 'working knowledge' is expected as the outcome, the proficient user of a course book is commonly exposed to fractional explanations and only collections of samples rather than exact clarification of the categories considered. The Communicative Approach to English Language Teaching seems to systematically exclude the method of structural linguistics from teaching the language, preferring purely semantic categorizing. This method may find its justification in the claim that detailed description of the language structure would be inconvenient for young learners and contradict the communicative approach to foreign language teaching. Nevertheless, the communicative approach might be subjected to scrutiny when it comes to the advanced levels $(\mathrm{C} 1+$ and $\mathrm{C} 2)$, where 
the target of foreign language teaching aims at achieving accuracy, i.e. perfection in using the grammar forms flawlessly.

To explain a grammar phenomenon and the formal and semantic nuances it may convey, one needs to rely on linguistic terminology, which has its unique potential to clarify the structural elements and functions transparently and efficiently. The present-day course-books provide their users with informal collocations and idioms, but accuracy in presenting grammar as well as formal register phrases remain supressed. In the Czech Republic, the requirements for future language teachers have traditionally been high. The focus on form is thus essential - incorporating in itself the usage of standardised linguistic terminology. But while the classes of practical language are being held alongside with the linguistic subjects, the future professional users of the English language perceive the discrepancies between their linguistic and practical terminology and categorizes employed, i.e. between their linguistic and practical language classes. The linguistic theory thus finds itself detached from 'school reality', on the other hand, the inquisitive learners may find the fuzziness of language description in practical course-books inadequate and misleading. This paper suggests that such practice should be altered, and the teaching materials at $\mathrm{C} 1-\mathrm{C} 2$ levels should take into account that their users are likely to be professionals, with the view of enabling them to clearly observe the links between their purely linguistic studies and their studies of 'practical language', or 'applied linguistics'. The research related to this paper lies in observing whether the following chosen grammatical phenomena are presented similarly in both linguistic and applied resources at the advanced levels.

For the purposes of this paper, the following basic grammatical phenomena were focused on as for the way these are presented in manuals at CPE level:

a) the categories of tense and aspect in the English language

b) the two major types of modality

Three manuals have been researched in detail, with a limited set of additional course-book resources which were part of the research:

Cambridge English Objective Proficiency, CUP 2013, 2015; Annette Capel, Wendy Sharp

Proficiency Masterclass, OUP 2012, 2016; Kathy Gude, Michael Duckworth, Louis Rogers

New Progress to Proficiency, CUP 2002 (first published in 1986, second edition 1993); Leo Jones 


\section{The categories of tense and aspect in the English language}

\subsection{The morpho-syntactic perspective}

In standard linguistic resources (Quirk et al., 1985) a clear distinction is postulated between the two categories. The authors define tense 1) on the basis of morphology as strictly expressed by inflection, 2) as a category primarily reflecting the present vs. past distinction, though they admit that 'the English present tense, for instance, usually, but by no means always, signifies present time.' 'This makes the usage of the term 'present tense' plausibly appropriate, but also potentially misleading' (Quirk et al., 1985, 175). Leech $(1971,1987,1992)$ maintains that the Present Tense in all its uses shares a basic association with the moment of speech. 'The state or event has psychological being at the present moment. This element of meaning does not exclude the possibility of its having actual being at a time other than the presents' (p. 5). This seems to make the ELT at all levels relatively complicated.

Lewis $(1986,1994)$ claims overtly that 'it is not characteristic of the present simple that it is associated with Present Time; the feature which all uses of the present simple share is that temporal reference is unnecessary' (p. 64). Lewis speaks of the Present Tense as of the base, or the unmarked form and suggests the term Basic Form as the one related to the terms of infinitive or imperative. This is, though, a disputable suggestion, given that in synthetic languages these categories do have their individual forms and the categories thus are well understandable to the learner (it is but a pleasant finding to them that the forms in English are less demanding to acquire).

Similarly to the present tense, the past tense has other functions in the grammatical system of the English language than that of denoting past processes. Leech $(1971,1987,1992)$ says that there are two types of meaning conveyed by the commonest use of the Past Tense, i.e. 'the normal use of the Simple Past: 1) 'the happening takes place before the present moment' - with the present moment being excluded, 2) 'the speaker has a definite time in mind' (p. 13). Leech mentions other uses of simple past, labelling them as 'hypothetical'. This corresponds with Quirk et al., who speak about a 1) a 'gap in time' between the completion of the action, or a similar gap the speaker has in mind (p. 183), or 2) indirect speech or thought, the attitudinal past, e.g. Did you want to see me now?, or hypothetical past used in subordinate clauses. (pp. 187-188). Similarly, Huddlestone and Pullum $(2005,2007)$ speak about three types of the preterite: a) past time, b) modal preterite (e.g. 'I'd rather they lived nearby' labelled as counter factuality or modal remoteness), c) backshift (p. 46-47).

Indisputably, the term 'remoteness' suggested by Lewis $(1986,1994)$ is a most suitable one, as it may be universally employed for all the basic areas of tense usage. 
In accordance with the standard linguistic resources, Lewis suggests: 'There is an underlying similarity of meaning of all uses of what is traditionally called 'the past simple'. The similarity is that in all cases the speaker conceptualises the action is factual but with an element of remoteness. The remoteness may be of different kinds - remoteness in time (the most common), remoteness of relationship, possibility, etc. The traditional 'indirect speech' uses are also remote.' (p. 74). This explanation brings clarity to the explanation of all the possible traditionally 'irrealis' propositions, such as the optative, the subjunctive mood types, or any hypothetical propositions.

On the other hand, the aspect is defined as 'a grammatical category that reflects the way in which the verb action is regarded or experienced with respect to time' (Quirk et al., 1985, p. 188). They then specify that the perfective aspect indicates ANTERIOR TIME, i.e. time preceding whatever time orientation is signalled by tense or other elements of the sentence or its context (p. 190). The meaning of the progressive aspect can be separated into three components: a) the happening has duration, $b$ ) the happening has limited duration, c) the happening is not necessarily complete (ibid.). The independence of aspect and tense is thus made unequivocal. Biber et al. (1999) use the following terms: Perfect aspect present tense, Perfect aspect past tense, Progressive aspect present tense, Progressive aspect past tense. All these four forms considered, the claim is supported that the two terms of tense and aspect, however they may combine within a verb phrase, should be pondered separately. Quirk et al. (1985) observe the effect the progressive aspect creates with state verbs, stance verbs, dynamic punctual verbs and transitional event/state verbs, and illustrate the effect of the combination of the two types of aspect, i.e. progressive and perfective on these sub-types of verbs. But one cannot disagree with Lewis, who postulates: 'Aspects give the speaker's temporal interpretation of the event. They do not refer to real time, but to psychological time - to the speaker's perception of the quality of the event.' (Lewis, 1986, 1994, p. 85). It is only necessary to reveal to the learner the basic notions behind the two types of aspect. With the perfective one, close to Quirk's term of anteriority, Lewis recommends the term 'retrospective', i.e. either present or past retrospective (corresponding with the past perfect). As for the progressive aspect, Lewis recommends as a classroom explanation to perceive the process not as a point, but rather as a period (I propose a toast vs. It is raining), or rather a limited period of time (I live in Oxford vs. I am living in Oxford).

Like the standard linguistic resources, Lewis ponders the completeness of the process:

We could alternatively say that the speaker sees the action as incomplete, but completable, already in the process of being completed. The topmost important 
aspect is how the speaker conceptualises the process. ... Non-continuous forms express the speaker's view of the event as a complete, unitary whole. In contrast, the 'continuous' forms express incompleteness, and in particular incompleteness in time.

Further on, 'Incompleteness in time' means that 'the speaker conceptualises the action as occurring for a period, and that this period is limited' - the event having limited duration. Lewis thus suggests the term durative forms. (Lewis, 1986, 1994, p. 91). Clearly, as for the tense-aspect combinations, we can conclude that it does not seem adequate to label the aspectual combination with tense as individual tenses.

Professor Dušková from Charles University in Prague concurrently best represents the Czech contrastive structural grammar. She provides a thorough description of the English grammatical system as compared with the Czech one, speaking about the 'temporal system of the English language' (Dušková, 1988, 2012). She ponders the similarities between the aspect-marked variants in English with the Czech category of 'vid' (dokonavý vs. nedokonavý, i.e. 'completed' or 'incompleted'). Though she points out that there are numerous limitations (namely with the perfective aspect, where the notion of 'completeness' is related only to telic verbs), for the progressive aspect at least there is a clear overlap with the Czech category of vid dokonavý-incomplete (pp. 241-242).

Though Dušková (1994) points out that the Czech category of vid is an inherent component of the Czech verb, while in English the corresponding progressive aspect concerns only the aspect-marked variant, I suggest that the following examples will suitably serve the purposes of ELT via a contrastive method: progressive aspect - I was doing - nedokonavý vid - dělal jsem, perfective aspect - I have done - dokonavý vid - udělal jsem.

We may also observe that both utterances above have a past connotation in Czech, stating that the activity rather than the action is finished. The past reference remains, regardless of the choice whether the action is finished completely I have done - udělal jsem or finished for the time given I was doing - dělal jsem. The Czech past tense will always be used, but what will differ is the category of vid, corresponding to that of the perfective or progressive aspects. On the other hand, one may even suggest the word-by-word translation of the first utterance - I have (it) done - as Mám (to) udéláno/Mám (to) hotovo (I have (it) finished). Then, again, the tense will be present like in English, but the category of vid corresponds again with the perfective aspect. Similarly, with state verbs, the meaning for the Czech of I have worked/have been working here for two years by now is present to a Czech, as it is to an English native (the hope for its continuation expressed by the progressive aspect plays little role in the perception of the present perfect, in other 
words the present tense). Thus the Czech language in a way, however different from English in terms of morphological classes of languages, supports the idea that the tense is a different category from the English aspect.

Turning back to Lewis $(1986,1994$, p. 87) and his postulating the speaker's importance in forming the proposition, one must accept the general point of the difference between grammar as fact and grammar as choice, so that the form in fact expresses the speaker's view of the event.

In other words, we can now conclude that the whole complexity of the different grammatical systems could be presented in a far more transparent way did we not insist on fragmenting the categories into a 'catalogue of terms and meanings', informing the learners that there are up to fifteen tenses in the English language. To a Czech learner, who only knows three, but who is likely to embrace the parallel with the category of vid in Czech, this is a material deterrent. The paradox of this all is the fact, that in the grammatical system of English, there are in fact only two tenses, i.e. fewer than in Czech. The solution for ELT seems to be three-fold. First, it lies in the systematic usage of terminology such as the tense and aspect described separately. Second, teachers need deeper insight in the system that will allow them to present some undeniable basic concepts, e.g. the notions of anteriority or retrospective. These are useful for learning and will not require their re-definition in the following stage of learning. Last but not least, at advanced and proficiency levels, grammar should not be perceived as a restriction, but it should already be perceived as a way of expressing the nuances users of the language bear in mind. It is not that we should serve grammar, but we should be able to use grammar as a tool to express the nuances we wish to.

\subsection{The CPE manuals}

\subsubsection{Cambridge English Objective Proficiency, CUP 2013, 2015; Annette Capel, Wendy Sharp:}

In Unit 1 of this course book, the following terms are listed: Perfect tenses: Present perfect simple tense, Present perfect continuous tense, Past perfect simple tense, Future perfect simple tense, Future perfect continuous tense.

We have observed the fact that the aspect and tense should be described separately, as their semantic applications differ, and to an advanced learner with analytical thinking such ad hoc terms are little transparent. The 'catalogues of rules and meanings' phenomenon, criticised by Lewis, is exemplary in this coursebook. For the 'Present perfect simple tense' the catalogue includes four items: 1) when talking about events or situations that started in the past and are still true (but how about 'I inherited this house from my parents'?), 2) when considering the present effects of something that happened in the past (but how about ' $I$ was 
born in 1980'?), 3) when addressing a recent event or situation (but how about 'I have been to Canada once ' - see Lewis's point about this 'rule' implausible as a general rule of grammar), 4) when referring to something that will happen at some time in the future (but how about 'I will be twenty in December'?). The universally applicable term of 'anteriority' or 'remoteness' are not mentioned.

Similarly, with the 'Past perfect simple tense', defined as a form used 'to refer to an event which took place before something else' does not provide any clear insight in the matter (how about 'I went to the library and they offered me a job there?'). The progressive aspect is similarly reduced in terms of the grammar folder in the book, providing only one ad hoc example to complete the "catalogue of rules' for all the progressive verb phrase alternatives.

Moreover, the authors do not reflect the possibility that its user is likely to have at least some linguistic knowledge and thus may find the terms utterly misleading; a learned proficiency student is well likely to know that a simple verb phrase consists of one verbal element exclusively, i.e. a simple verb phrase only includes the lexical verb, e.g. I drive. If complex, the verb/predicate incorporates auxiliary verbs - up to four of them, such as in the following example. A complex VP:

Table 1. Verb phrase with auxiliaries

\begin{tabular}{|c|c|c|c|c|}
\hline operator & auxiliary $_{2}$ & auxiliary $_{3}$ & auxiliary $_{4}$ & head \\
\hline$(\mathbf{o})$ & $\left(\mathbf{x}_{2}\right)$ & $\left(\mathbf{x}_{3}\right)$ & $\left(\mathbf{x}_{4}\right)$ & $(\mathbf{h})$ \\
\hline will & have & been & (being) & done \\
\hline
\end{tabular}

Stating that a 'Past perfect simple tense' or 'Future perfect simple tense' exist contradicts both the early prescriptive and the later descriptive grammars, including Quirk et al, Biber et al, Leech or Swan. The course-book does not show any such reflection provided by Lewis $(1986,1994)$ either; the brief list of examples by no means corresponds with the proficiency level.

\subsubsection{Proficiency Masterclass, OUP 2012, 2016; Kathy Gude, Michael Duckworth, Louis Rogers}

The terms employed in this course-book seem, to some extent, more appropriate, their headings being the following: Narrative Tenses, Perfect Aspect, Stative Verbs, Simple or Continuous.

In Unit 1 the authors mention past verb forms, respectively past simple (even to express distance from present reality, hypothetical situations, less direct requests and offers), past continuous and past perfect. The Grammar Reference Section thus incorporates more technical terminology, but still, both the explanations and examples found in the actual studying material (exercises found in the unit) are largely limited. 
In Unit 4 the Perfect Aspect is re-visited (though only as a part of the set of Present simple, Present Continuous, Present Perfect). The category of the perfect aspect seems inadequately represented for a proficiency level, with the related exercises at a rather mediocre level.

In Unit 7 the Continuous Aspect and Stative Verbs are introduced and presented at a satisfactory level in the 'Grammar Reference Section, with detail included. (Further exercises, though, are needed and must be provided from other resources outside the course-book.)

One of such additional resource-books is Advanced Grammar in Use by Hewings (1999). Not only does this publication offer a more intensive insight into the tendencies in favour of the progressive aspect in contemporary English (though his course-book claims to correspond to the 'advanced' rather than proficiency levels), but it is far more systematic in terms of Lewis' 'general rules' (though the linguistic terms are not specific). The explanations in the Proficiency Masterclass course-book only pick examples at random without further clarification of the matter.

\subsubsection{New Progress to Proficiency, CUP 2002 (first published in 1986, second edition 1993); Leo Jones}

As for the category of aspect, only the meanings are revised in Unit 7.4, labelled as Grammar review - Past and Present (p. 78). No distinct linguistic terminology is used, no presentation designed, the nuances in meaning are meant to be explained by paraphrasing. This approach seems to reflect the utmost tendencies in ELT of the period, where the 'Communicative Approach' in ELT was experiencing its climax. Nonetheless, Leo Jones' course-books are in all other respects acknowledged as most brilliant and highly recommendable. Even grammar-wise, there are definite pros to be pointed out: numerous working examples are provided and they offer a rich language resource for the learner at the proficiency level.

\section{The two major types of modality}

\subsection{The morpho-syntactic perspective}

'At its most general, modality may be defined as the manner in which the meaning of a clause is qualified so as to reflect the speaker's judgement of the likelihood of the proposition it expresses being true' (Quirk et al., 1985, p. 219). This brief semantic definition only establishes a framework within which the authors distinguish the following two types of modality: intrinsic (expressing permission, 
obligation, volition, which involve some kind of intrinsic human control over events) and extrinsic (expressing such notions as possibility, necessity and prediction, 'which do not primarily involve human control of events, but do typically involve human judgement of what is or is not likely to happen' (ibid.) Quirk points out that there is a gradient between these two types. This may have led numerous grammarians to speculate about the modals as 'so extremely messy and untidy 'that' the most the linguist can do is to impose some order, point out some regularities, correspondences, parallelisms' (Lewis, 1994). Thus there occur ambiguities in recognising the intended modality with modal verbs such as will, where one intended meaning might be prediction (extrinsic), while the other one, i.e. volition (intrinsic) is also possible; thus, in accordance with Quirk, we may conclude that a modal auxiliary verb commonly has both a) intrinsic and b) extrinsic meanings. If so, the same modal meaning can be expressed by more modal verbs, while other than prototypical modal verbs are also part of the set of verbal exponents used to carry the function. Biber et al. (1999) speak about nine central modal auxiliary verbs used to express modality (can, could, may, might, shall, should, will, would, must), marginal auxiliaries (need to, ought to, dare to, used to), taking 'auxiliary negation' and yes-no question inversion, and the socalled semi-modals/quasi-modals/periphrastic modals (e.g. have to, be going to, be able to, be willing to etc.), which can carry the categories of tense and person, and can occur as non-finite forms, thus combining with central modal auxiliaries within one verb phrase, e.g.: The county council will have to ask colleagues to bid for money on its behalf (Biber et al., 1999, p. 484). Standard academic resources also point out the possibility to group the central modals into pairs with related meaning (with the exception of must), one member of the pair representing the original present tense form, while the other corresponding modal can refer to past time: can - could, may - might, shall - should, will - would. Of course, we now regard modal verbs as unmarked for tense (Biber, et al., 1999, p. 485), as the past tense forms are commonly used to denote present or future processes. However, the question arises whether sticking to the old distinction would not bring more light to the understanding of the matter of modality within ELT.

Lewis $(1986,1994)$ defines the modal auxiliaries, i.e. the prototypical carriers of modal meaning (can, could, shall, should, may, might, will, would, must) as a group which always behave similarly, and which behave similarly to each other as follows: 1) They occupy the first place in a complex verb phrase, 2) They do not co-occur, 3) They are used as operators in the formation of questions, negatives, etc., 4) They share important semantic similarities. (p. 101). The speaker's interpretation of non-factuality, maintains Lewis, is an enormously broad concept which may include such notions as speculations, guesses, estimates, idealisations (p. 102). But Lewis seeks the primary semantic characteristics first, before the communicative meanings, which are numerous (p. 103). 
Accordingly, he insists that understanding the verbs shall and will as modal auxiliaries is crucial (rather than their denoting 'the future tense', still acknowledged by some grammarians, including Dušková (1994), although she acknowledges their modal character). As Lewis (1986, 1994, p. 100) puts it,

[...] accurate sorting is a prerequisite of accurate description; the traditional dissorting of these items has been a source of much confusion. Recognising them as modal auxiliaries helps clear the way for deeper understanding of their primary semantic characteristic.

Amongst the communicative modal meanings, Lewis randomly lists semantic 'elements of possibility, necessity, desirability, morality, doubt, certainty, etc.', but one might easily suggest many others, such as deniability, admittance or uncertainty. Lewis presents the following set of examples: He's coming. He's probably coming. He might come (p. 101). With the first example being nonmodal, one can notice it is presented as a fact. The phenomenon of non-factuality related to modal-marked utterances stands out as a crucial one here. Similarly, the modal meaning can be paraphrased and defined. Lewis thus identifies the principal meaning of can as possibility, while this can be sub-categorised, into e.g.: ability - which stands for 'it is possible for me to do it: Can you swim? possibility decided by rules: You can't smoke in here, offers: Can I give you a lift?, deduction-logical possibility: He can't be French. The same distinction is observed with the past tense functions, i.e. the function of expressing 'remoteness' is correspondingly applicable with the modals: unlike can, could represents remoteness in time, relationship, likelihood (p. 112).

With a somewhat mathematical approach, Lewis also addresses the difference between must (subjective necessity) and have to (objective necessity) and the position of must as the exceptional central modal auxiliary which does not seem to have a 'past tense counter-part'. He explains that as must refers to speaker's (subjective) perception of necessity, as soon as the speaker recalls the event in Past Time where something was necessary, that necessity becomes objective, hence had to is employed automatically (p. 111).

However eye-opening Lewis' suggestion might be, I believe that the structural linguist who acknowledges the distinction made between the intrinsic (root/deontic) modality and the extrinsic one would bring more light to teaching modality at advanced levels. This is most evident when we refer to past events and situations; with extrinsic/epistemic modality, the speaker 'modalizes' at speech time about a situation anterior to the speech time - or remote to the speech time; thus logically we combine the modal verb with perfect infinitive denoting such an anterior process. Lewis provides a useful insight into the broad concept of 
modality. On the other hand, traditional structural grammarians, such as Quirk, Biber or Dušková, provide the learner with reasonable categorizing. In coursebooks, however, they are the 'catalogues of rules and meanings' that are likely to prevail.

\subsection{The CPE manuals}

\subsubsection{Cambridge English Objective Proficiency, CUP 2013, 2015; Annette Capel, Wendy Sharp:}

In unit 4 an ad hoc term of 'Speculating about the past' is employed, where the users are advised to use the terms 'a modal + have + past participle'. The extrinsic/ epistemic modality is thus presented (without the terms being mentioned) as serving the following three functions and applications: 1) to express certainty or near-certainty about something in the past, the modal verb must is used with have and a past participle; 2) to express uncertainty about something in the past, the modals verbs could, may, might are used with have and a past participle; 3 ) to express impossibility about something in the past, the modal verbs can't or couldn't are used with have and a past participle (p. 180). Another question arises here, i.e. whether could and could not are or are not 'the same modal verb'. The terminology used is highly inconsistent for the level considered.

A similar method of grammar presentation is employed where 'using the passive in the past' is introduced. There are only two passive infinitives that are commonly used in English, the present and the perfect forms: This yoghurt needs to be eaten before $25^{\text {th }}$. Radical cuts to the budget seem to have been made by the managing director. Again, the term of 'anteriority' (or remoteness), which would serve the logic of the explanation, or any other logical paraphrase is avoided.

In unit 6 the 'Degrees of likelihood' are announced; the explanatory content includes the following six sentences: 1) can is used to express possibility without reference to past, present or future (He can sound off-key at times when he sings.); 2) could, may and might express present possibility with reference to the future, present or past; 3) may not and might not express possibility negatively (a most misleading semantic concept; how about: This might not be useless indeed?) 4) Deduction is expressed by must be / must have been / will be / will have been and should be / should have been (then, how about might be/might have been?); 4) Impossibility is expressed by cannot/can't and could not. 5) could and might can be used to imply criticism or irritation (the modal expression in 'could be used' - contradicts the term of rule at all); 6) could and might can be used to imply criticism or irritation (e.g. You might have told me you'd be coming late). An appropriate comment follows, i.e. that 'intonation is very important in carrying meaning with those modals' (p. 181). 
In unit 18, where the grammar part is labelled as 'Modals review', 11 semantic categories are listed as follows: 1) Strong obligation, 2) Weak obligation, 3) Unfulfilled obligation (past), 4) Prohibition, 5) No necessity, 6) Speculation, 7) Deduction, 8) Ability, 9) Impossibility, 10) Advice, 11) Permission. The distinction between the two basic types of modality is not mentioned, nor the clarification related to the past reference. The presentation thus seems to correspond to a lower intermediate grade of presentation, rather than a proficiency one.

\subsubsection{Proficiency Masterclass, OUP 2012, 2016; Kathy Gude, Michael Duckworth, Louis Rogers}

Again, the presentation of the field of modality appears as highly unsystematic. The ad hoc terms used are those of 'prediction', 'possibility', 'necessity', 'deduction', 'obligation', 'modals with have + past participle'. No attempt is made to clarify the background idea presentable as a general rule, such as Lewis tries to introduce to ELT, occurs in the course-book. The distinction between intrinsic and extrinsic modality is not explained either, the logic of using the perfect aspect (perfect infinitive) with extrinsic modality is missed out.

\subsubsection{New Progress to Proficiency, CUP 2002 (first published in 1986, second edition 1993); Leo Jones}

The modal expression in English is only presented in the course-book as a list of modal meanings, revised in Unit 7.4. However, no linguistic terminology is employed. Epistemic/extrinsic modality is the main point, but the combination with perfect infinitive to 'modelise' upon anterior events is not included. The nuances in meaning are explained exclusively by paraphrasing ('discuss the meaning'). Like with the categories of tense and aspect, the author avoids theoretical notions and sticks to the communicative approach, covering the grammar items by their functions exclusively.

\section{The CAE course-books - pilot study}

\subsection{New English File - Advanced, OUP 2010; Clive Oxenden and Christina Latham-Koenig}

The term of 'aspect' is not mentioned in the book. Unit 2 only includes the subtitle 'the past: narrative tenses', in Unit 3 'unreal uses of past tenses' are announced. The term past tenses, though, suggests, that the authors have no problem to speak about many more English past tenses. Three simple rules follow, worded in the 
form of imperative, e.g.: Use the past simple to talk about the main actions in a story. The authors mention the usage of used to and would, and an interesting point is made there: 'Used to and would make it clear that you are talking about something that happened regularly and often convey a sense of nostalgia.' (p. 139). I dare suggest that such an explanation does not provide clarity as it could easily be disproved. However, the important difference between the two forms is overlooked. In Unit 3, the 'unreal uses of the past tenses' (again in plural) are introduced; examples are given, accompanied by instructions (We use..., We sometimes use ..., You can also use ...). I believe that the generally applicable notion of remoteness from time/reality would be most helpful as an appropriate explanation (p. 144).

Modality is presented as part of Unit 3A and Unit 5A. The former deals with the extrinsic/epistemic modality, but is labelled as 'Speculation and deduction'; it seems useful, though, that the two types of modal meanings are not covered at the same time, which commonly produces a rather 'disorganised' way of presenting the matter of modality in general. The authors use the term of 'the perfect infinitive', but do not explain why it is employed in the structures listed. In Unit $5 \mathrm{~A}$ the intrinsic/deontic modality are pondered without mentioning the term, though; the terms used are of purely semantic character (permission, obligation, necessity).

\subsection{Advanced expert CAE, Longman 2014, 2017; Jan Bell, Roger Gower, Drew Hyde}

The authors introduce the tense and aspect in Unit 1 of the book but avoid using the categories overtly. They label the sub-chapter as 'Mixed verb forms': present and past (simple, perfect and continuous). The presentation on the 'Grammar page' (p. 173) provides a proto-typical 'catalogue of meanings' with such concepts as 'thinking of past and present together' or 'recent past' (as meanings of the present prefect), which are criticised by Lewis as they are not generally applicable, and thus cannot establish a 'rule'. Similarly, the authors postulate that 'past tenses are used to describe situations in the present, past or future which are imagined or unreal', further on 'to indicate that the situation is unlikely'. Clearly, a better defined general rule would suit the presentation far more effectively.

The modal verbs are presented and practised in two units of the book, using such terms strong opinion about a fact, controlling possible action, or deductions as distinguished from possibility or probability. The distinction between intrinsic and extrinsic modality is blurred by these ad hoc terms, and little clarity is thus imported to the advanced user. Notes such as the following, listed but never explained logically, only underline the superficiality of the language presentation: 
'Need has two past forms with different meanings: She didn't need to take a coat. It wasn't cold. (We don't know if she took a coat or not.) She needn't have taken a coat. (She took one, but it wasn't necessary)' (p. 178).

\subsection{English Unlimited, CUP 2011; Adrian Doff and Ben Goldstein}

The book has been released in Cambridge, New York, Melbourne, Madrid, Cape Town, Singapore, Sao Paulo, Dehli, Dubai, Tokyo, Mexico City, thus it is probably a material designed by the authors as a universal, multi-cultural resource. This seems to have put paid to the advance level of grammar and formal register. The grammar topics have been thoroughly marginalised in this publication, being reduced into randomly chosen topics, all introduced in the Grammar parts by a set of ad hoc created terms such as: Will and would, Adverbs, Talking about change, Passive reporting verbs or Whatever.

The tense and aspect are tackled in Unit 2 of the book, under the heading of 'Verb tenses in narration'. Four forms of verb phrases are summed up here: Past simple, Past Progressive, Past Perfect Simple and Past Perfect Progressive. The term 'state verbs' is mentioned with respect to the progressive forms, but every piece of information is minimalized with one example presented only for each function. Would and was going are added to that list. In Unit 6, Present Perfect is the grammar focus. Present Perfect Simple is defined as a form used 'to refer to events in a period 'up to now', to announce news, with the events connected with the present (we can see the result now) (p. 142). With Present Perfect Progressive, the authors come back to the notion of 'state verbs', list a group of them and point out that they 'are not normally used in the progressive form'. The whole presentation is though concise and does not substantially expand the topic any further.

As for the modals, there are only two introduced as part of the Grammar reference: Will and Would in Unit 1. The authors present their 'habitual use' (will as equivalent to present simple and would to past simple), then they go on to list nine different functions of these two modal verbs, not taking into consideration the extrinsic and intrinsic types of the modal meaning.

\section{Conclusion}

Over the last three decades, evident discrepancies have been found between standard structural linguistic resources and ELT manuals/handbooks at the proficiency level. That is concerned with both the manner of explaining the linguistic phenomena 
such as tense, aspect or modality but also the terms and categories perpetuated in the course-books. The authors of common studying materials for advanced learners thus appear to be either lacking the standard linguistic knowledge or overlooking it as dispensable for the learner. This apparently stems from the general policy of the prevailing 'Communicative Approach Methodology', whose core principle is to teach students to communicate to various degrees of fluency, rather than understand the linguistic system and become accurate. In other words, this methodological approach has long outweighed striving for deeper insight in the very subject matter, i.e. the language itself. If the course-books are in general designed so as to appeal to the user and present the language material in a most upto-date manner (including the political bias of a period), the focus on system and form will always be supressed. As for the linguistic terminology - the categories of morphology and syntax are thus rarely employed in the manuals.

The main thrust of this paper is to draw our attention to the terms, categories and ways of presentation which occur in a selected set of modern CPE and CAE course-books. The author observes to what extent and relevance the linguistic terms are reflected in these practical resource-books and provides comments based on both perspectives: the linguistics proper and applied linguistics.

This paper has also attempted to confront the standard linguistic resources with the lexical approach introduced by Lewis, who considers the idea of 'catalogue of rules/meanings' recurring in course-books as misguided. He submits the strategy of presenting rules which are gradually disclaimed and re-defined to criticism, and suggests for the students to be hinted at some general rules or concepts such as remoteness for past tense form of the verb, or anteriority/remoteness for the perfect aspect.

It must be pointed out that the contrastive method is often most effective, including the analytical translation (see the useful comparison of the category of aspect and vid in Czech).

Last but not least, the topic is closely related to another field of university discourse; students of pedagogy, who specialise in the English studies as future English teachers, often comment on the redundancies with which the linguistic disciplines operate, perceiving linguistic disciplines as detached from the 'real language usage' and 'classroom practice'. I believe that the better the teacher novice understands the language system, the better they are prepared and equipped to enter the classroom and provide their students with learned answers to those enquiring 'why-questions'. The author of this paper suggests that a sound knowledge of the language system and clearly defined terminology benefits to all participants in the second language teaching and learning processes. 


\section{References}

Bell, J., Gower, R., \& Hyde, D. (2005, 2007). Advanced expert CAE. Harlow: Longman.

Biber, D., Johansson, S., Leech, G., Conrad, S., Finegan, E., \& Quirk, R. (1999). Longman Grammar Of Spoken and Written English (Vol. 2). London: Longman.

Capel, A., Sharp, W. (2013, 2015). Cambridge English Objective Proficiency. Cambridge: CUP. Doff, A., Goldstein, B. (2011). English Unlimited. Cambridge: CUP.

Dušková, L. (1994, 1998, 2012). Mluvnice Současné Angličtiny na Pozadi Češtiny. Praha: Academia.

Gude, K., Duckworth, M., Rogers, L. (2012, 2016). Proficiency Masterclass. Oxford: OUP.

Hewings, M. (2013). Advanced Grammar in Use. Cambridge: CUP.

Huddleston, R., Pullum, G. K. (2005, 2014). A Student's Introduction to English Grammar. Cambridge: CUP.

Jones, L. (1986, 1993). New Progress to Proficiency. Cambridge: CUP.

Leech, G. (1987). Meaning and the English Verb, Second Edition. Harlow: Longman House.

Lewis, M. (1986, 1994). The English Verb; An Exploration of Structure and Meaning. Hove: Langue Teaching Publications.

Oxenden, C., Latham-Koenig, C. (2010). New English File - Advanced. Oxford: OUP.

Quirk, R., Greenbaum, S., Leech, G., \& Svartvik, J. (1985). A comprehensive Grammar of the English Language. London, GB: Longman.

Swan, M. (1980). Practical English Usage. Oxford: OUP. 